\title{
Acceptability and feasibility of a virtual community of practice to primary care professionals regarding patient empowerment: a qualitative pilot study
}

Carlos Jesús Bermejo-Caja ${ }^{1,11}$, Débora Koatz ${ }^{2,3}$, Carola Orrego ${ }^{2,3}$, Lilisbeth Perestelo-Pérez ${ }^{4,3}$, Ana Isabel González-González ${ }^{3,6,6 *}$, Marta Ballester ${ }^{2,3}$, Valeria Pacheco-Huergo ${ }^{7}$, Yolanda del Rey-Granado ${ }^{1}$, Marcos Muñoz-Balsa', Ana Belén Ramírez-Puerta ${ }^{1}$, Yolanda Canellas-Criado ${ }^{8}$, Francisco Javier Pérez-Rivas ${ }^{9}$, Ana Toledo-Chávarri, ${ }^{3,10}$, Mercedes Martínez-Marcos ${ }^{11}$ and e-MPODERA group

\begin{abstract}
Background: Virtual communities of practice (VCoPs) facilitate online learning via the exchange of experiences and knowledge between interested participants. Compared to other communities, vCoPs need to overcome technological structures and specific barriers. Our objective was to pilot the acceptability and feasibility of a vCoP aimed at improving the attitudes of primary care professionals to the empowerment of patients with chronic conditions.
\end{abstract}

Methods: We used a qualitative approach based on 2 focus groups: one composed of 6 general practitioners and the other of 6 practice nurses. Discussion guidelines on the topics to be investigated were provided to the moderator. Sessions were audio-recorded and transcribed verbatim. Thematic analysis was performed using the ATLAS-ti software.

Results: The available operating systems and browsers and the lack of suitable spaces and time were reported as the main difficulties with the VCOP. The VCoP was perceived to be a flexible learning mode that provided up-todate resources applicable to routine practice and offered a space for the exchange of experiences and approaches.

Conclusions: The results from this pilot study show that the VCoP was considered useful for learning how to empower patients. However, while vCoPs have the potential to facilitate learning and as shown create professional awareness regarding patient empowerment, attention needs to be paid to technological and access issues and the time demands on professionals. We collected relevant inputs to improve the features, content and educational methods to be included in further VCoP implementation.

Trial registration: ClinicalTrials.gov, NCT02757781. Registered on 25 April 2016.

Keywords: Empowerment, Primary healthcare, Virtual system, Healthcare professional attitudes, Pilot study

* Correspondence: aisabel.gonzalezg@salud.madrid.org

${ }^{3}$ Red de Investigación en Servicios de Salud en Enfermedades Crónicas

(REDISSEC) ISCIII, Madrid, Spain

${ }^{5}$ Institut für Allegemeinmedizin. Johann Wolfgang Goethe-Universität,

Theodor-Stern-Kai 7, 60590 Frankfurt am Main, Germany

Full list of author information is available at the end of the article

(c) The Author(s). 2019 Open Access This article is distributed under the terms of the Creative Commons Attribution 4.0 International License (http://creativecommons.org/licenses/by/4.0/) which permits unrestricted use, distribution, and reproduction in any medium, provided you give appropriate credit to the original author(s) and the source, provide a link to the Creative Commons license, and indicate if changes were made. The Creative Commons Public Domain Dedication waiver (http://creativecommons.org/publicdomain/zero/1.0/) applies to the data made available in this article, unless otherwise stated. 


\section{Background}

Knowledge is key to the advancement of organizations. Learning and the implementation of practices, however, does not only rely on explicitly developed knowledge. Discussion, interaction, observation and the exchange of experiences between professionals all aid understanding of formal knowledge, which thus acquires meaning in line with proposals regarding social theories of learning [1], and imply an interaction between socially defined competences and personal experiences [2]. The community of practice $(\mathrm{CoP})$ is one strategy that facilitates this type of learning [3].

A CoP, coined as a term in the 1990s [4], is, according to Wenger [5] "not just a website, a database, or a collection of best practices. It is a group of people who interact, learn together, build relationships, and in the process develop a sense of belonging and mutual commitment". Having others who share their overall view of the domain and yet bring their individual perspectives on any given problem creates a social learning system that goes beyond the sum of its parts. A CoP reflects a common field (depending on the competences of the group) delimiting what is of interest to the group, the existence of a structure that encourages interaction and relationships among members, shared practices and a repertoire of resources such as ideas, experiences and information. A CoP differs from other types of groups in that support takes the form of formal and informal interactions between members and that the emphasis is on voluntary participation, shared learning and knowledge and the fostering of a sense of belonging [5]. While CoPs have largely developed in the business and education areas, they are increasingly being used in the health sector [6-10].

Information communication technologies have led to great growth in virtual $\mathrm{CoP}$ ( $\mathrm{vCoPs}$ ) in recent years, given their greater flexibility, ease and speed of communication compared to other communities [11]. However, their establishment involves more than merely importing the content of traditional communities into a new framework. Technological structures need to be created and barriers not present in face-to-face communities need to be overcome, mainly related to the fact that members may be many, located in different geographical areas, not know each other and can have different organizational cultures. Further barriers are related to the availability and use of the new technologies [12, 13].

Many of these limitations can be overcome by using discussion forums and video-conferencing for real-time exchanges and by appointing a facilitator to promote a greater sense of commitment and presence of participants and to manage content and resources [14, 15]. Online learning benefits from this type of communities of primary care professionals, related to a better management of their time constraints and to possible geographic barriers, promoting networking and collaboration. Online learning has also shown beneficial results in changing attitudes, increasing knowledge and skills, as well as possible benefits in patients' related outcomes [16].

A recent review [13] found that vCoPs allow professionals to be attracted to interprofessional learning activities and collaboration among them that break down professional silos and barriers related to isolation, establishing a risk-free environment for participants that increases their participation and involvement. vCoPs allow the possibility for professionals to be involved in activities that promote interprofessionalism, an important aspect for the provision of quality care and the goal of accomplishing better health outcomes.

We developed a vCoP named e-MPODERA, a pun combining the terms "empower" and "e-learning techniques", aimed at improving primary care professionals' attitudes to the empowerment of patients with chronic conditions.

e-MPODERA vCoP was created as a gamified virtual knowledge-sharing $\mathrm{CoP}$ based on a Web 2.0 platform that offers learning activities and materials regarding patient's empowerment. This platform uses forums as a main tool aimed at sharing experiences, practices and resources, and makes collaborative learning a powerful way for sharing knowledge, sensitize for empowerment concepts and develop real solutions to specific problems using open and inclusive technologies. The activities were designed using a competence framework based on 4 learning objectives and 12 core competences (Table 1 ). Gamification is based on ranking, points, goals and badges, added to interactive contents, like games, videos, and other individual and collaborative tasks. Content was developed considering patients' health literacy and self-efficacy, self-monitoring, shared decision-making, coping capacities, etc. Some of the main subjects tackled were: attitudes towards empowerment, dimensions of empowerment, health literacy, share decision making, self-management, communication skills, special morbidity cases (i.e. obesity, diabetes mellitus, ischemic heart disease, lung disease, elderly patient, falls prevention, stroke, dementia), care of the caregiver, etc.

The objective of the present study was to pilot the acceptability and feasibility of the e-MPODERA vCoP before testing its effectiveness to improve primary care professionals' attitudes to the empowerment of patients with chronic conditions in a cluster randomized control trial [17].

\section{Methods}

Study design

We used thematic analysis to perform this descriptive qualitative study [18]. Data was collected using the focus group technique because interactions between the 
Table 1 Framework of learning objectives and competences

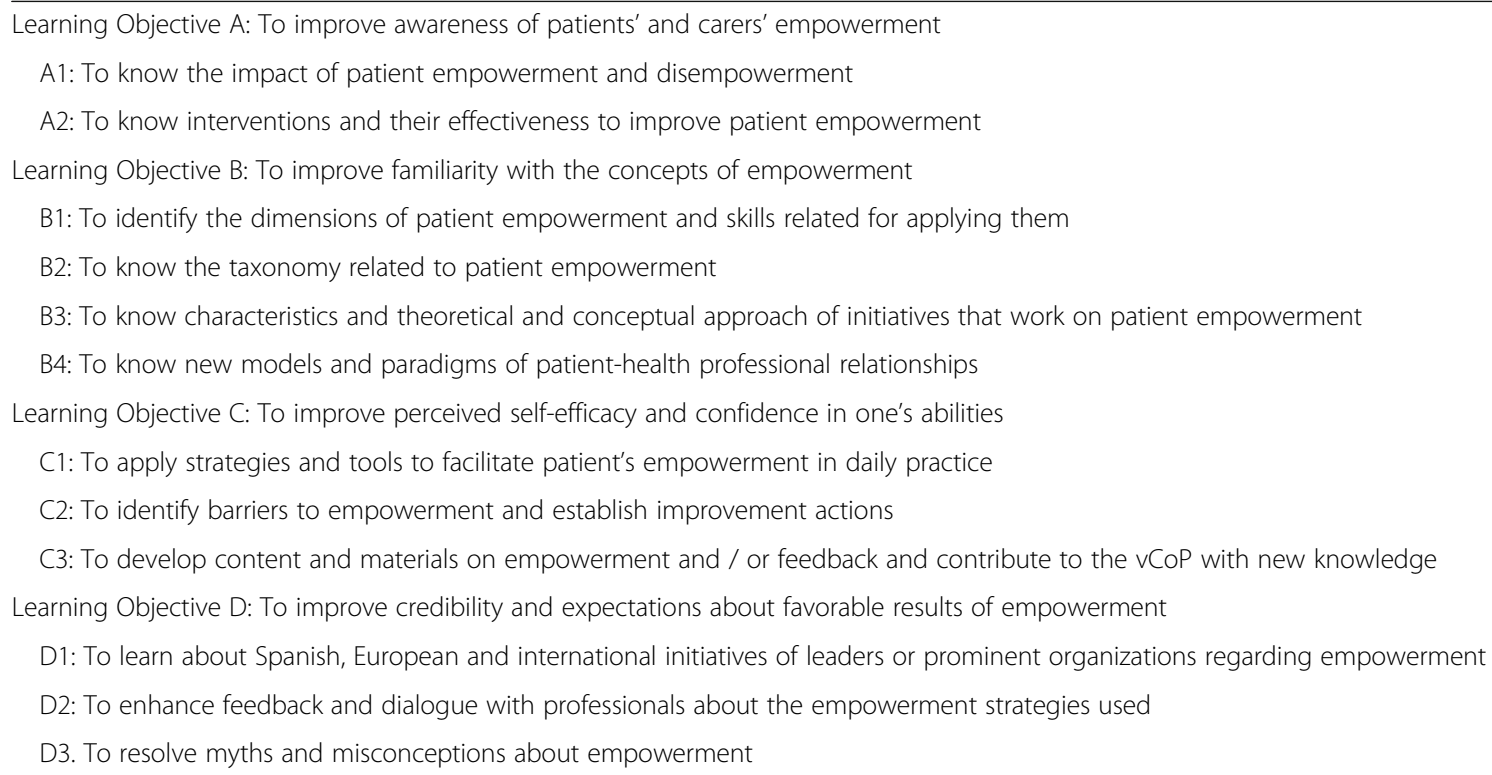

participants enable them to share and reflect on their experiences [19]. The study was designed in accordance with the Consolidated Criteria for Reporting Qualitative Research (COREQ), a 32-item checklist for interviews and focus groups [20] (Additional file 1).

\section{Setting}

The study was carried out in 3 urban general practices in the Madrid region attended to by 38 General Practitioners (GPs) and 35 Practice Nurses (PNs), with an assigned population of 63,298 people.

\section{Participants}

We purposively sampled for the focus group discussions 12 professionals, 6 GPs and 6 PNs, out of the 26 professionals that participated in the e-MPODERA vCoP, considering not only their level of participation in the vCoP (high, medium and low), based on the degree of participation in forums, comments and entries on the platform, but also age, sex and experience in primary care (Table 2).

During the piloting, content was gradually incorporated into the $\mathrm{vCoP}$ over a 4-month test period (June to September 2016). All participants entered the $\mathrm{vCoP}$ and $31 \%$ contributed with comments. The topics inviting most comments were health literacy, shared decisionmaking and communication.

\section{Procedure}

Two focus group sessions were held, one with 6 GPs and the other with 6 PNs, in November 2016. The focus group sessions lasted between 60 and $90 \mathrm{~min}$, were held in a neutral venue and were facilitated by a moderator
(CJBC), who led the discussion, and 2 assistants (YR, $\mathrm{MMB})$, who took notes and audio-recorded the sessions. The moderator and assistants were qualitative researchers with training and experience in the field and with no direct relationship with the participants. Each group session commenced with a description of the objectives and a request for consent to both participation and audio-recording. After each group session, the moderator and assistants discussed the sessions and also took notes at these meetings.

We prepared guidelines for the focus group which contained the topics to be explored (Table 3), although the moderator was also allowed to inquire further regarding issues that emerged during the sessions.

\section{Data analysis}

The interviews were audio-recorded and later transcribed verbatim. Two researchers (CJBC, MMM) first read the transcriptions for both groups in their totality to ensure familiarity with the texts. Using a thematic analysis approach, the transcriptions were then coded independently by the 2 researchers (CJBC, MMM) using the ATLAS.ti software program, with open coding followed by categorization and abstraction.

Following the steps identified by Braun \& Clarke [21], we followed six simple steps to conduct a thematic analysis: 1) familiarizing ourselves with the data; 2) generating initial codes; 3) searching for themes; 4) reviewing the themes; 5) defining and naming the themes; 6) preparing the report.

Researchers (CJBC, MMM) met regularly to discuss and debate findings until consensus was reached [22, 23]. To enhance validity, findings were reviewed by other 
Table 2 Socio-demographic characteristics of the participants in the focus groups

\begin{tabular}{llllll}
\hline ID number & Focus group & Age & Sex & $\begin{array}{l}\text { Primary care } \\
\text { experience } \\
\text { (years) }\end{array}$ & $\begin{array}{l}\text { vCoP } \\
\text { participation } \\
\text { level }^{\text {a }}\end{array}$ \\
\hline GP 01 & 1 & 53 & M & 25 & Medium \\
GP 02 & 1 & 46 & M & 17 & Low \\
GP 03 & 1 & 51 & F & 23 & High \\
GP 04 & 1 & 58 & F & 34 & Medium \\
GP 05 & 1 & 62 & F & 27 & Low \\
GP 06 & 1 & 50 & F & 17 & Low \\
PN 01 & 2 & 42 & F & 19 & Low \\
PN 02 & 2 & 47 & F & 19 & Low \\
PN 03 & 2 & 42 & F & 17 & Low \\
PN 04 & 2 & 60 & F & 10 & High \\
PN 05 & 2 & 29 & M & 3 & Medium \\
PN 06 & 2 & 60 & F & 28 & Low \\
\hline
\end{tabular}

GP: general practitioner $(n=6)$; PN: practice nurse $(n=6)$

${ }^{a}$ The level of participation was defined considering the degree of participation in forums, commentaries and entries in the platform

members of the research team who contributed to the thematic analysis. The findings were transmitted to the focus group participants to obtain their feedback [19].

\section{Ethics}

The study complied with Good Clinical Practice standards and the principles of the latest version of the Helsinki Declaration (Brazil, 2013) and was approved by the Clinical Research Ethics Committee of Ramón y Cajal University Hospital in Madrid (ACTA 303), Nuestra Señora de Candelaria University Hospital in Santa Cruz de Tenerife (PI-18/16) and IDIAP Jordi Gol in Barcelona (C2748). Confidentiality and anonymity were guaranteed in accordance with Spanish Law 15/1999 on personal data protection and all participants in the study gave their informed consent.

\section{Results}

The participants expressed great interest in the vCoP learning environment, which allowed them to access content even from home and at times that suited them always using a personal computer. They

Table 3 Focus group guidelines (topics)

\footnotetext{
-Problems that have hindered participation in the $\mathrm{VCoP}$

- Reasons for participating or not participating in the VCoP

- $\mathrm{VCOP}$ barriers to improving patient empowerment

-How could the VCOP and e-MPODERA bring about change in professional

practice that promoted patient empowerment?

-What resources would foster this change?

-How do you think this kind of vCoP improve the exchange of knowledge?

-What activities would you like the vCoP to offer?

-What activities would you like to eliminate from the vCoP?

-The role of the VCoP facilitator
}

highlighted the usefulness of $\mathrm{vCoP}$ material like tutorials, videos and demonstrations, indicating that this content led them to reflect on how they approached clinical practice; they also reported that the interaction with other professionals led them to contemplate other approaches to address the empowerment of patients with chronic conditions. However, they pointed some difficulties in accessing the vCoP.

See Table 4 for more detailed information on the emerging themes and subthemes.

\section{vCoP: a novel kind of training}

Clinical practice is perceived by the participants as taking place in a context of multiple demands - by the organization, the population and society as a whole. The participants referred to the need to have new and up-to-date resources, easily implemented as a work aid and capable of responding effectively to the needs of patients with chronic conditions while adapting to the context of their health centre.

The vCoP was viewed as a learning mode that met participants needs through activities that could be accessed in a flexible way according to the time available, including from home.

\section{"And it's practical, they give you a day a week when, if you want, you can see the class live and it's a video-conference and if you download anything it's recorded and you watch it when you can, the hour and a half or two hours that the class lasts and then you see the instructor, who explains things and you ask. I find that very useful." PN 04}

This form of learning was considered of interest insofar as it could provide the participants with useful materials, defined as up-to-date resources allowing easy access from the point of consultation and responding to the needs of patients. GPs perceived a greater need for this type of information accessible at the point of care, information not available to them from other available resources.

\section{"Specific things that help us, that facilitate things with the patient because we do not have time ... and when you don't have time, of course, you can't be there, looking through a hundred thousand things to see which is the most interesting." GP 05}

In relation to the potential of the $\mathrm{vCoP}$ as a training element, the professionals indicated that it should contain up-to-date, specifically primary care work-related and evidence-based information previously selected as especially relevant by those responsible for development of the vCoP. This information should also be easily accessible from the point of consultation in order to ensure more rapid answers than provided by existing resources. 
Table 4 Emerging themes and subthemes

\begin{tabular}{lll}
\hline THEME & THEME & THEME \\
\hline Novel kind of training & Benefits for patient empowerment & Difficulties using vCoP \\
SUBTHEMES & SUBTHEMES & SUBTHEMES \\
$\begin{array}{l}\text { Flexible accessibility for learning } \\
\text { Provision of useful materials in }\end{array}$ & Opportunity to reflect on their own clinical practice & Technological difficulties \\
$\begin{array}{c}\text { consultation } \\
\text { Information based on evidence }\end{array}$ & Share tips and demonstrations. & Tutorials that do not facilitate the use \\
Possible ways to address problems & Interaction / exchange of experiences among & of the platform \\
Motivation for learning & professionals & Information in non-native language \\
& Resources to motivate the chronic patient & No availability of time to access the \\
& & work environment \\
& & Little ease for access from home \\
\hline
\end{tabular}

"If you had that information directly, scientific of course, in 5 minutes you could read it or a summary paragraph. Many of the platforms do not address that and if we have to find things ourselves, we have to do very exhaustive searching that takes a long time." GP 02

Regarding the opportunities offered by the vCoP for interaction and the exchange of experiences, mainly through forums and interactive video-conferencing sessions, participants indicated that this helped them consider alternative approaches to similar problems or clinical situations applicable to routine practice. Both groups of professionals considered useful opportunities for interaction and exchange of experiences with other professionals.

"I found them very interesting because I found them useful for practice ... with the patients, to deal with some issues that maybe hadn't occurred to me, that I'd looked at superficially, to notice and consider them." GP 01

For the vCoP to become consolidated as a training tool, it requires the appointment of an individual or team to select relevant and easily accessible information from the large amount of information available and to assume a motivational role in encouraging professionals to enter the community, consult information, participate in forums, etc. ... figure that both PNs and GPs considered necessary.

"Facilitators. People who filter maybe and who help us a little with managing things at a specific moment. The most important things. So that you don't have to, what she said before, access a load of information, that there's a kind of filter of what's most important or most relevant." GP 06

\section{vCoP: benefits for patient empowerment}

The vCoP activities were considered, by both groups of professionals, to be an opportunity to examine and reflect on approaches to chronic patients in their clinical practice and to analyse alternative approaches. Tutorials and demonstration videos were considered especially useful as they enabled patients to be managed from a more comprehensive perspective with the goal of empowering them.

"... I was doing activities, many that I found very appropriate and good for teaching. The truth is, they even make you think a little and elaborate on things. It made you discuss sometimes ... what you usually do in consultations." GP 01

The nurses placed more emphasis on the usefulness of the vCoP in terms of tips and demonstrations that could be used with their patients to address specific issues

"That's what I was referring to, like when someone helps you see the light, so [ you tell the patient] 'protect the fingertips' or 'take some holidays,' those phrases that seem silly when it comes to consulting, I used them." PN 02

New approaches and ways of doing things, as one participant commented, could be learned from the opinions, judgements, experiences and procedures of other professionals. The interaction between professionals fostered by the $\mathrm{vCoP}$ was considered to be an opportunity to advance learning.

"... you access to see more things, to see what they comment, the impressions of another person, the game that's played between colleagues, what one does, what the other does, we could learn new ways of acting." GP 01

Some expectations were not fulfilled by the $\mathrm{vCoP}$ in this pilot phase, specifically by the PN group. These include the availability, to use during consultations, of previously prepared resources aimed specifically at reinforcing patient knowledge. Among these resources, special mention was made of information resources for patients or to work conjointly with them. 
"Yes, maybe a library of resources with teaching materials to help the patient would be useful, which we, in the consultation ... well, if they are young or are used to the internet, we could easily download useful information on their chronic illnesses and give them that didactic material to train them too." PN 05

Since one frustration for professionals was patients not adhering to guidelines or advice, a suggestion was to include resources aimed at stimulating the interest of patients in addressing adherence, as both GPs and PNs manifested.

"As a professional, maybe I miss some kind of methodology to motivate them, some line or strategy, that's to say, techniques or something, you know? To emphasize things so they leave the consultation motivated to say, you're right, you know what I mean?” PN 02

\section{vCoP: difficulties using it}

During the focus group sessions, the study participants pointed to several difficulties with using the eMPODERA vCoP, with the main difficulty generally related to access issues.

Participants referred to great difficulty in using vCoP in their workplace, since the computers there had operating systems and browsers that made it difficult to access the platform. This technical difficulty was due to equipment obsolescence, not to participant capacity to use the technology, and there were no differences in this respect between the GPs and PNs. When software problems, such as inexplicable system crashes and error messages, occurred during workplace use, the professionals became frustrated and stopped using the tool.

"If at work in the centre it's impossible, we don't have access, access is impossible. You click, it blocks, the page stays blank, you go back and it's just impossible." PN 04

Not all work centres had the same difficulties, as some centres with up-to-date computer equipment offered better accessibility.

Another access difficulty for participants was to find a suitable space and time to use the $\mathrm{vCoP}$ in a meaningful way. Both GPs and PNs reported how the burden of patient care and administrative tasks consumed their working hours, leaving very few opportunities for innovation and learning. Consequently, many participants reported accessing the $\mathrm{vCoP}$ from home, although here too fitting access in with family demands was not always easy.
"Then the times that I've been able to connect have always been at home, which just seemed a bit ... uff. Because then from home, it depends on things, because you have more or less time." PN 05

Other difficulties described by the participants referred to access to the virtual platform itself. It was always necessary for the user to remember their user name and password information, and options to recuperate this information were less than satisfactory. In general, PNs expressed more difficulties related to limitations on access to the platform.

"For me in practice access has sometimes been difficult. The first part, doing the survey went very well, that was easy. Then you go back and what's the password. I took a photo and even with a photo it was difficult to access." PN 02

The tutorial designed to facilitate use of the $\mathrm{vCoP}$ was not considered useful, given its location in the platform and the fact that it was considered complicated.

"Well, other than that, the tutorial was a bit complicated. We talked to one of them [on the platform] and I think it was located in ... or in another place, because it was at the side, right? The truth is I did not understand very well at the beginning, when I got into the tutorial." GP 03

While most of the documents and activities for use by the professionals were in Spanish, some were in English. Because the professionals, specially the PN group, had to use online translators, these documents were less consulted and less likely to be read and used.

"I would ask just one thing, it's probably also my ignorance. That not everything would be, that not much information would be in English." PN 02

\section{Discussion}

Professionals generally viewed virtual learning environments like e-MPODERA vCoP with interest. Use of the Internet for ongoing training purposes has increased in recent years. In the health area, a significant percentage of health professionals use the Internet daily for workrelated reasons, mainly to locate information for patients, but also for self-managed ongoing training via online reading and learning activities [24].

Participants in the study considered important to have up-to-date equipment and resources that responded to the needs posed by patients in consultations, and most especially, information that was not available from other 
resources, as the goal is to be able to provide rapid responses. Participants preferred to have resources that they could use in routine practice, such as demonstration videos and educational materials, but available in the local language. Barnett [25] confirms that perceived usefulness is a key predictive factor in any intention to use a vCoP.

The $\mathrm{vCoP}$ was perceived as an encyclopaedia that would always be available for use when necessary [26]. Barnett [25] reported that the resources most valued by doctorsin-training and tutors are the possibility of sharing clinical practice guidelines and other documents, followed by discussion forums. The sustainability and maturation of a $\mathrm{vCoP}$ relies on resources such as technical documents, demonstration materials, videos, photos, etc. available in repositories or in information sections in external websites [10, 27-29]. Another advantage of the $\mathrm{vCoP}$ pointed out by participants was that general or specific information was available almost immediately [30]. As McLoughlin et al. [13] outlined, this aspect is key for the engagement of professionals in the vCoP.

Participants also emphasized the speed of responses from the rest of their team $[25,28]$. Indeed, interaction between the vCoP participants in general was considered to be crucial, as it offered the opportunity to exchange experience, to learn of alternative approaches to patients with chronic conditions, to examine, reflect on and analyse other perspectives related to routine practice and to observe the skills and even practical demonstrations of other participants. The most valued $\mathrm{vCoP}$ areas regarding the empowerment of chronic patients were the forums and interactive sessions such as video-conferences with external experts.

Interaction between $\mathrm{vCoP}$ participants is an aspect highlighted in other studies, not only in relation to exchanging documentation, but also in terms of resolving doubts and problems through the contributions of other participants sharing experiences and exchanges aimed at improving knowledge and skills [26, 29, 31]. Interaction between professionals in the same field of work in normal working conditions is crucial, and in a vCoP, the interaction format that generates the most shared knowledge is that which combines face-to-face and online interactions, followed by face-to-face interactions [25, 28, 31]. Barnett [29] reported that participants using a vCoP stated that they benefited mainly from online interactions aimed at generating trusting relationships, but also from the confidence generated by prior knowledge shared by participants.

Certain barriers to interaction were identified. Active participation by all members was considered by some participants to be crucial for the proper functioning of the $\mathrm{vCoP}$ [29]. Indeed, under-participation can lead to failure of this form of learning [13]. Even so, the less active participants were of the opinion that they also benefited from reading the contributions of the other participants, even though they themselves could not participate actively, for instance, due to a lack of time [29]. In some cases, nonparticipation was due to a fear that a contribution might be trivial or irrelevant [30]. However, in most vCoP $90 \%$ of participants act as observers and never contribute, 9\% contribute just occasionally and $1 \%$ are always active [32]. As McLoughin et al. showed [13], several strategies have been reported to increase participation such as increasing trust among members, focusing $\mathrm{vCoP}$ on common interests or focusing $\mathrm{vCoP}$ on the patient by providing resources based on easily accessible evidence.

The vCoP facilitator played an important role, according to the participants in the study. A facilitator motivates members to participate and also helps by filtering more relevant and important information, especially that based on evidence. On the other hand, facilitators play an important role in ensuring clear rules, focusing the discussions and promoting the involvement and respect among the members [13]. In this study, the facilitator was a primary care professional who participated by leading and developing the vCoP. In different vCoPs analysed by Barnett [33] the facilitator may be the person who initiates and launches the $\mathrm{vCoP}$ or may emerge from the group of participants, especially from among more active participants. The role of facilitators is usually to enhance cooperation, but they also can ensure that the rules of engagement are clear, ensure focus on discussions, establish procedures for member inclusion and lead commitment to and maintenance of the vCoP. The facilitator also identifies relevant content and saves it correctly to bring it back when it is necessary [9]. In this study, clinically active facilitators were key to the development of the $\mathrm{vCoP}$ in terms of recognizing the contributions of participants and in guiding them [29,33]. Another contribution of the facilitators was notifying new entries and frequent participants.

A vCoP needs a technological infrastructure that will support online operation and use and so requires more careful design than traditional learning formats. As pointed out by Barnett [33], ensuring that a technology is easy to use enhances the potential success of a $\mathrm{vCoP}$. In our study we observed difficulties fundamentally related to access, such as obsolete or incompatible browsers and the lack of suitable additional software to access all the available resources. Another identified difficulty was the need to create and remember an access password. Such difficulties lead to frustration and abandonment of vCoPs.

Other difficulties identified by the professionals that participated in our study are common to the ones found in the literature $[24,31,33-36]$ such as slow connections, problems downloading information and documents, workplace restrictions on Internet access by employees, incompatibilities with tablets and mobile phones and audio problems. 
The main difficulty reported by the professionals in our study was a lack of time, which hinder access to learning environments, especially from the workplace [35]. The main advantage of a vCoP for professionals, according to previous studies [26, 31], is the flexibility of this kind of learning environment, as it allows access at the time and in the place considered most convenient. Most professionals in piloting of the e-MPODERA vCoP preferred to access the $\mathrm{vCoP}$ resources from home (43.9\%), followed by those who accessed from both home and work (33.2\%) [24]. Technical problems, as corroborated by several authors $[24,31,37]$, combined with a lack of time at work led many participants to use the $\mathrm{vCoP}$ in the home setting, even though they would have preferred use in the workplace as most suitable from a training perspective.

One limitation of the study is that it was carried out in 3 urban, city-based, general practices (in Madrid) and so excluded rural centres. Therefore, it was not possible to access the perceptions of professionals working in more isolated settings. Besides, only a limited number of professionals were invited to participate in this pilot study (26 primary care professionals) and vCoP enrich with the participation of more professionals, not being able to reach a saturation of the speech. Another limitation was that the duration of use of the $\mathrm{vCoP}$ ( 6 months) was probably not long enough for relationships of trust between the participants and a feeling of belongingness in a community to develop. The difficulties accessing the platform did not help in this matter. Finally, perceptions of the $\mathrm{vCoP}$ may have been affected by the fact that participants in the study, while employed by the Madrid Health Service, work in different autonomously managed health centres; thus, exchanges between professionals may have been limited by a certain homogeneity in the organizational criteria of the different centres.

Table 5 Facilitators and barriers to the use of the vCoP

Facilitators
The use of information and knowledge technologies allows the
development of vCoP with flexible accessibility for the training of
health professionals.
The inclusion of evidence-based and updated materials is a necessary
and useful tool for healthcare activity.
Maintaining and providing useful and updated information motivates
the use and functioning of the vCoP.
The vCoP is a medium that allows interaction between professionals
from different locations and enables sharing approaches, opinions,
experiences and ways of performing.
The presence of easy-to-understand tutorials, with the necessary infor-
mation for the use of vCoP, would improve access to the included re-
sources and participation.
Barriers
The use of out-of-date or inappropriate hardware and software limits
and hinders access to and participation in a vCoP.
The inclusion of documents and resources in non-native language
causes difficulties in understanding information.
The time restrictions in work environments can limit access to a vCoP.

\section{Conclusions}

The results from this pilot study show that the eMPODERA vCoP was considered useful for learning how to empower patients. However, attention needs to be paid to technological issues, and the time demands on professionals. We collected relevant inputs to improve the features, content and educational methods to be included in further vCoP implementation (Table 5).

\section{Additional file}

Additional file 1: COREQ (COnsolidated criteria for REporting Qualitative research) Checklist. (PDF 497 kb)

\section{Abbreviations}

CoP: Community of Practice; e-MPODERA: Effectiveness of a Virtual Intervention to Improve Healthcare Professional Attitudes to Patient Empowerment;

GP: General Practitioner; PN: Practice Nurse; vCoP: Virtual Community of Practice

\section{Acknowledgements}

The authors would like to thank Ailish M J Maher for translating the article into English.

e-MPODERA Group:

Concepción Alejo-Díaz Zorita.

Centro de Salud Caramuel, Gerencia Asistencial de Atención Primaria,

Servicio Madrileño de Salud, Calle Fuenteovejuna 17, 28011 Madrid, Spain.

Email: concepcion.alejo@salud.madrid.org

Cynthia A. Barbero-Macías.

Centro de Salud Monóvar, Gerencia Asistencial de Atención Primaria, Servicio

Madrileño de Salud, Calle Monóvar 11, 28033 Madrid, Spain.

Email: cynthiaakira.barbero@salud.madrid.org

Fernando Borrell-Punzón.

Centro de Salud Caramuel, Gerencia Asistencial de Atención Primaria,

Servicio Madrileño de Salud, Calle Fuenteovejuna 17, 28011 Madrid, Spain.

Email: fernando.borrell@salud.madrid.org

Beatriz Bueno-Rodriguez.

Centro de Salud Caramuel, Gerencia Asistencial de Atención Primaria,

Servicio Madrileño de Salud, Calle Fuenteovejuna 17, 28011 Madrid, Spain.

Email: bbueno@salud.madrid.org

Begoña Colmena-Martin.

Centro de Salud Caramuel, Gerencia Asistencial de Atención Primaria, Servicio Madrileño de Salud, Calle Fuenteovejuna 17, 28011 Madrid, Spain.

Email: begona.colmena@salud.madrid.org

Isabel del Valle-de Joz.

Centro de Salud Caramuel, Gerencia Asistencial de Atención Primaria,

Servicio Madrileño de Salud, Calle Fuenteovejuna 17, 28011 Madrid, Spain.

Email: isabel.valle@salud.madrid.org

Juan Carlos Gamboa-Puñal.

Centro de Salud Caramuel, Gerencia Asistencial de Atención Primaria,

Servicio Madrileño de Salud, Calle Fuenteovejuna 17, 28011 Madrid, Spain.

Email: juancarlos.gamboa@salud.madrid.org

Concepción García-Valverde.

Centro de Salud Caramuel, Gerencia Asistencial de Atención Primaria,

Servicio Madrileño de Salud, Calle Fuenteovejuna 17, 28011 Madrid, Spain.

Email: concha.garcia@salud.madrid.org

Luis Miguel Gómez-Garzón.

Centro de Salud Monóvar, Gerencia Asistencial de Atención Primaria, Servicio

Madrileño de Salud, Calle Monóvar 11, 28033 Madrid, Spain.

Email: luismiguel.gomez@salud.madrid.org

Arturo Gómez-López.

Centro de Salud Vicente Muzas, Gerencia Asistencial de Atención Primaria,

Servicio Madrileño de Salud, Calle Vicente Muzas 8, 28043 Madrid, Spain.

Email: arturo.gomez@salud.madrid.org

Alejandro Hernaz-Guijo.

Centro de Salud Monóvar, Gerencia Asistencial de Atención Primaria, Servicio

Madrileño de Salud, Calle Monóvar 11, 28033 Madrid, Spain.

Email: alejandro.hernaz@salud.madrid.org 
Walter Nery Herrera-León.

Centro de Salud Caramuel, Gerencia Asistencial de Atención Primaria, Servicio Madrileño de Salud, Calle Fuenteovejuna 17, 28011 Madrid, Spain. Email: walternery.herrera@salud.madrid.org

Irene Iniesta-González.

Centro de Salud Vicente Muzas, Gerencia Asistencial de Atención Primaria, Servicio Madrileño de Salud, Calle Vicente Muzas 8, 28043 Madrid, Spain. Email: irene.iniesta@salud.madrid.org

Margarita Leza-Leza.

Centro de Salud Vicente Muzas, Gerencia Asistencial de Atención Primaria, Servicio Madrileño de Salud, Calle Vicente Muzas 8, 28043 Madrid, Spain. Email: margarita.leza@salud.madrid.org

María Aránzazu Melchor-Canelo.

Centro de Salud Monóvar, Gerencia Asistencial de Atención Primaria, Servicio Madrileño de Salud, Calle Monóvar 11, 28033 Madrid, Spain.

Email: mariaarantzazu.melchor@salud.madrid.org

Sagrario Muñoz-Quirós Aliaga.

Centro de Salud Monóvar, Gerencia Asistencial de Atención Primaria, Servicio

Madrileño de Salud, Calle Monóvar 11, 28033 Madrid, Spain.

Email: smunozq@salud.madrid.org

Ángela Oria-Fernández.

Centro de Salud Vicente Muzas, Gerencia Asistencial de Atención Primaria, Servicio Madrileño de Salud, Calle Vicente Muzas 8, 28043 Madrid, Spain. Email: angela.oria@salud.madrid.org

Nuria Pertierra-Galindo.

Centro de Salud Monóvar, Gerencia Asistencial de Atención Primaria, Servicio Madrileño de Salud, Calle Monóvar 11, 28033 Madrid, Spain.

Email: nuria.pertierra@salud.madrid.org

Ma Dolores Prieto-Barbosa.

Centro de Salud Caramuel, Gerencia Asistencial de Atención Primaria,

Servicio Madrileño de Salud, Calle Fuenteovejuna 17, 28011 Madrid, Spain.

Email: mprietob@salud.madrid.org

Milagros Robledo-Vázquez.

Centro de Salud Vicente Muzas, Gerencia Asistencial de Atención Primaria, Servicio Madrileño de Salud, Calle Vicente Muzas 8, 28043 Madrid, Spain.

Email: milagros.robledo@salud.madrid.org

Marta Ruiz-López.

Centro de Salud Vicente Muzas, Gerencia Asistencial de Atención Primaria, Servicio Madrileño de Salud, Calle Vicente Muzas 8, 28043 Madrid, Spain.

Email: marta.ruiz@salud.madrid.org

M Carmen Sánchez-Cruz.

Centro de Salud Vicente Muzas, Gerencia Asistencial de Atención Primaria, Servicio Madrileño de Salud, Calle Vicente Muzas 8, 28043 Madrid, Spain. Email: mscruz@salud.madrid.org

Ma Ángeles Sánchez-de Eusebio.

Centro de Salud Vicente Muzas, Gerencia Asistencial de Atención Primaria, Servicio Madrileño de Salud, Calle Vicente Muzas 8, 28043 Madrid, Spain. Email: mseusebio@salud.madrid.org

Ma Jose Seijas-Martínez Echevarría.

Centro de Salud Vicente Muzas, Gerencia Asistencial de Atención Primaria, Servicio Madrileño de Salud, Calle Vicente Muzas 8, 28043 Madrid, Spain. Email: mariajose.seijas@salud.madrid.org

Carmen Paola Tovar-García.

Centro de Salud Vicente Muzas, Gerencia Asistencial de Atención Primaria, Servicio Madrileño de Salud, Calle Vicente Muzas 8, 28043 Madrid, Spain.

Email: mcpaola.tovar@salud.madrid.org

Jose Ignacio Vicente-Diez.

Centro de Salud Monóvar, Gerencia Asistencial de Atención Primaria, Servicio Madrileño de Salud, Calle Monóvar 11, 28033 Madrid, Spain.

Email: joseignacio.vicente@salud.madrid.org

Cristina Villanueva-Sanz.

Centro de Salud Vicente Muzas, Gerencia Asistencial de Atención Primaria, Servicio Madrileño de Salud, Calle Vicente Muzas 8, 28043 Madrid, Spain. Email: cvillanueva@salud.madrid.org

\section{Authors' contributions}

CO conceived the study, participated in its design, coordinated all phases of the trial, is the principal investigator (PI) for the Catalonian region and collaborated proofreading the manuscript. AIGG conceived the study, participated in its design, is the PI for the Madrid region and collaborated with the first draft and final writing of the manuscript. LPP conceived the study, participated in its design, is the PI for the Canary Islands region and collaborated proofreading the manuscript. CJBC conceived the study, participated in its design, is the co-PI for the Madrid region and collaborated with the first draft and final writing of the manuscript. CJBC coordinated the pilot testing of the VCoP in Madrid, organized the focus groups and led the discussions. CJBC and MMM analyzed and interpreted professionals' data. YRG, MMB, ABRP, YCC and FJPR contributed with the implementation of the $\mathrm{VCOP}$ in the primary centers and in the different phases of the pilot study. DK, MB contributed developing the VCOP. JCGP, MRV, BBR, DPB, MRL, JIVDPTG, FBP, BCM, MAMC, SMA, CBM, NPGAHG, LMGG, CVS, CSC, AGL, AOF, MJSE, ASE, MLL, IIG, WNHL, CGVIVJ and CAZ participated in the piloting of the VCOP and as members of the focus groups. All authors read and approved the final manuscript.

\section{Funding}

This study was financed by Instituto de Salud Carlos III and Cofinanced by Fondo Europeo de Desarrollo Regional (FEDER). Ministerio de Economía y Competitividad. Gobierno de España. (PI15/00164, Pl15/00586, Pl15/00566). Dr. Ana Isabel González-González.

The funding source played no role in study design, data collection, analysis or interpretation, or the writing of the manuscript. The researches retain complete independence in the conduct of the study. The FIS evaluation committee will annually inspect study progress and adherence to the study protocol.

\section{Availability of data and materials}

Not applicable.

\section{Ethics approval and consent to participate}

The study fulfils GPC standards and the principles of the latest version of the Helsinki Declaration (Brazil, 2013). The project has been approved by the Clinical Research Ethics Committee of Ramón y Cajal University Hospital in Madrid (ACTA 303), Nuestra Señora de Candelaria University Hospital in Santa Cruz de Tenerife (PI-18/16) and IDIAP Jordi Gol in Barcelona (C2748). In accordance with Spanish Law 15/1999 on personal data protection, confidentiality and anonymity is guaranteed. We obtained written informed consent from all participants.

\section{Consent for publication}

Not applicable.

\section{Competing interests}

The authors declare that they have no competing interests.

\section{Author details}

'Unidad de Apoyo Técnico, Gerencia Asistencial de Atención Primaria, Servicio Madrileño de Salud, Calle San Martín de Porres 6, 28035 Madrid, Spain. ${ }^{2}$ Instituto Avedis Donabedian, Universidad Autónoma Barcelona, Calle ProvenÇa 293 pral, 08037 Barcelona, Spain. ${ }^{3}$ Red de Investigación en Servicios de Salud en Enfermedades Crónicas (REDISSEC) ISCIII, Madrid, Spain. ${ }^{4}$ Servicio de Evaluación y Planificación, Dirección del Servicio Canario de la Salud, Centro de Salud El Chorrillo, Camino Candelaria s/n, 38109, El Rosario, Santa Cruz de Tenerife, Spain. Institut für Allegemeinmedizin. Johann Wolfgang Goethe-Universität, Theodor-Stern-Kai 7, 60590 Frankfurt am Main, Germany. ${ }^{6}$ Centro de Salud Vicente Muzas, Gerencia Asistencial de Atención Primaria, Servicio Madrileño de Salud, Calle Vicente Muzas 8, 28043 Madrid, Spain. ${ }^{7}$ EAP Turó, Vilapicina 8 C, Barcelona, Spain. ${ }^{8}$ Centro de Salud Monóvar, Gerencia Asistencial de Atención Primaria, Servicio Madrileño de Salud, Calle Monóvar 11, 28033 Madrid, Spain. ${ }^{9}$ Departamento de Enfermería, Facultad de Enfermería y Podología, Universidad Complutense de Madrid, Plaza Ramón y Cajal, s/n, 28040 Madrid, Spain. ${ }^{10}$ Fundación Canaria de Investigación Sanitaria, Centro de Salud El Chorrillo, Camino Candelaria s/n, 38109, El Rosario, Santa Cruz de Tenerife, Spain. " ${ }^{1}$ Departamento de Enfermería, Universidad Autónoma de Madrid, Calle Arzobispo Morcillo 4, 28029 Madrid, Spain.

Received: 11 December 2018 Accepted: 28 May 2019

Published online: 20 June 2019

\section{References}

1. Bandura A. Social learning theory. Jersey city: Prentice Hall; 1977.

2. Wenger E. Communities of practice and social learning systems. Organization. 2000;7:225. 
3. Li LC, Grimshaw JM, Nielsen C, Judd M, Coyte PC, Graham ID. Evolution of Wenger's concept of community of practice. Implement Sci. 2009;4(1):11.

4. Lave J, Wenger E. Situated learning: legitimate peripheral participation. Cambridge: Cambridge University Press; 1991.

5. Wenger E. Communities of practice and social learning systems: the career of a concept. In: Blackmore (eds.) Social learning systems and communities of practice. Springer, London; 2010. p. 179-98

6. Ranmuthugala G, Cunningham FC, Plumb JJ, Long J, Georgiou A, Westbrook Jl, et al. A realist evaluation of the role of communities of practice in changing healthcare practice. Implement Sci. 2011;6(1):49. Available from: http://www.implementationscience.com/content/6/1/49.

7. Rolls K, Kowal D, Elliott D, Burrell AR. Building a statewide knowledge network for clinicians in intensive care units: knowledge brokering and the NSW intensive care coordination and monitoring unit (ICCMU). Aust Crit Care. 2008;21(1):29-37. Available from: http://www.ncbi.nlm.nih.gov/ pubmed/18226542.

8. Johnson C. A survey of current research on online communities of practice. Internet High Educ. 2001;4(1):45-60.

9. Mendizabal GA, Solinís RN, Zaballa González I. HOBE+, A case study: a virtual community of practice to support innovation in primary care in Basque public health service. BMC Fam Pract 2013;14(1):168-186. Available from: https://doi.org/10.1186/1471-2296-14-168\%5Cnhttp://search.ebscohost.com/ login.aspx?direct=true\&db=aph\&AN=91844754\&site=ehost-live

10. Lai KW, Pratt K, Anderson M, Stigter J. Literature review and synthesis: online communities of practice [internet]. Education. 2006:99. Available from: http://www.educationcounts.govt.nz/_data/assets/pdf_file/0019/ 7480/lrs-online-com.pdf.

11. Russell J, Greenhalgh T, Boynton P, Rigby M. Soft networks for bridging the gap between research and practice: illuminative evaluation of CHAIN. Bmj. 2004;328(7449):1174. Available from: http://www.bmj.com/content/328/ 7449/1174.abstract\%5C, http:/www.bmj.com/content/328/7449/1174. full\%5C, http://www.bmj.com/content/328/7449/1174.full.pdf.

12. Sharma RC. Constructing identities in online communities of practice - by Leila Kajee. Br J Educ Technol. 2009 Sep;40(5):965-966. Available from: https://doi.org/10.1111/j.1467-8535.2009.01009_4.x

13. McLoughlin C, Patel KD, O'Callaghan T, Reeves $\mathrm{S}$. The use of virtual communities of practice to improve interprofessional collaboration and education: findings from an integrated review. J Interprof Care. 2018:32(2):136-42.

14. Tolson D, Booth J, Lowndes A. Achieving evidence-based nursing practice: impact of the Caledonian development model. J Nurs Manag. 2008;16(6): 682-91. Available from: http://www.ncbi.n/m.nih.gov/pubmed/18808462.

15. Curran JA, Murphy AL, Abidi SSR, Sinclair D, McGrath PJ. Bridging the gap: knowledge seeking and sharing in a virtual community of emergency practice. Eval Health Prof. 2009;32(3):312-25. Available from: http://www. ncbi.nlm.nih.gov/pubmed/19696084.

16. Reeves S, Fletcher S, Mcloughlin C, Yim A. Interprofessional online learning for primary healthcare: findings from a scoping review. BMJ Open. 2017;7:e016872.

17. González-González Al, Orrego C, Perestelo-Pérez L, Bermejo-Caja CJ, Mora N Koatz $D$, et al. Effectiveness of a virtual intervention for primary healthcare professionals aimed at improving attitudes towards the empowerment of patientes with chronic diseases: study protocol for a cluster randimized controlled trials (e-MPODERA project). Trials. 2017;18:505.

18. Sandelowski M, Barroso J. Classifying the findings in qualitative studies. Qual Health Res. 2003;13:905-23.

19. Berenguera A, Fernández de Sanmamed M, Pons M, Pujol E, Rodríguez D, Saura S. Escuchar, observar y comprender. Recuperando la narrativa en las Ciencias de la Salud. Aportaciones de la investigación cualitativa. Barcelona: Institut Universitari d'Investigació en Atenció Primària Jordi Gol (IDIAP J. Gol); 2014.

20. Tong A, Sainsbury P, Craig J. Consolidated criteria for reporting qualitative research (COREQ): a 32-item checklist for interviews and focus groups. Int J Qual Health Care. 2007;19(6):349-57. Available from. https://doi.org/10.1093/ intqhe/mzm042

21. Braun V, Clarke V. Using thematic analysis in psychology. Qual Res Psychol. 2006;3(2):77-101. Available from. https://doi.org/10.1191/ 1478088706qp063oa.

22. Graneheim U, Lundman B. Qualitative content analysis in nursing research: concepts, procedures and measures to achieve trustworthiness. Nurse Educ Today. 2004;24(2):105-12. Available from: http://linkinghub.elsevier.com/ retrieve/pii/S0260691703001515.
23. Elo S, Kyngäs H. The qualitative content analysis process. J Adv Nurs. 2008; 62(1):107-15. Available from. https://doi.org/10.1111/j.1365-2648.2007.04569.x.

24. MacWalter G, McKay J, Bowie P. Utilisation of internet resources for continuing professional development: a cross-sectional survey of general practitioners in Scotland. BMC Med Educ. 2016;16(1):24. Available from: http://www.biomedcentral.com/1472-6920/16/24.

25. Barnett S, Jones SC, Bennett S, Iverson D, Robinson L. A virtual Community of Practice for general practice training: a Preimplementation survey. JMIR Med Educ. 2016;2(2):e13. Available from: http://mededu.jmir.org/2016/2/ e13/.

26. Ardichvili A, Page V, Wentling T. Motivation and barriers to participation in virtual knowledge-sharing communities of practice. J Knowl Manag. 2003; 7(1):64-77. Available from. https://doi.org/10.1108/13673270310463626.

27. Schlager M, Fusco J. Teacher professional development, technology and communities of practice: are we putting the cart before the horse? In: Barab $\mathrm{S}$, Klig R, Gray J, editors. Designing for virtual communities in the service of learning. Cambridge: Cambridge University Press; 2004. p. 120-53.

28. Murad A, Lederman R, Bosua R, Chang S, Wark JD. Enhancing general practitioners participation in a virtual community of practice for continuing medical education: an exploratory study. Stud Health Technol Inform. 2017; 239:97-103. Available from: https://www.ncbi.nlm.nih.gov/pubmed/ 28756443.

29. Barnett S, Jones SC, Caton T, Iverson D, Bennett S, Robinson L. Implementing a virtual Community of Practice for family physician training: a mixed-methods case study. J Med Internet Res. 2014;16(3):e83. Available from: http://www.jmir.org/2014/3/e83/.

30. Probst $\mathrm{G}$, Borzillo $\mathrm{S}$. Why communities of practice succeed and why they fail. Eur Manag J. 2008;26(5):335-47. Available from: http://linkinghub. elsevier.com/retrieve/pii/S0263237308000479.

31. Goh J, Clapham M. Attitude to e-learning among newly qualified doctors. Clin Teach. 2014;11(1):20-3. Available from. https://doi.org/10.1111/tct.12117.

32. Nielsen Norman Group. The 90-9-1 rule for participation inequality in social media and online communities [internet]. 2006. Available from: https:// www.nngroup.com/articles/participation-inequality/. [cited 4 Nov 2018].

33. Barnett S, Jones SC, Bennett S, Iverson D, Bonney A. General practice training and virtual communities of practice - a review of the literature. BMC Fam Pract. Dec;13(1):87. Available from. https://doi.org/10.1186/14712296-13-87.

34. Barnett S, Jones SC, Bennett S, Iverson D, Bonney A. Usefulness of a virtual community of practice and web 2.0 tools for general practice training: experiences and expectations of general practitioner registrars and supervisors. Aust J Prim Health. 2013;19(4):292. Available from: http://www. publish.csiro.au/?paper=PY13024.

35. Barnett S, Jones SC, Bennett S, Iverson D, Bonney A. Perceptions of family physician trainees and trainers regarding the usefulness of a virtual Community of Practice. J Med Internet Res. May;15(5):e92. Available from: http://www.jmir.org/2013/5/e92/.

36. Bennett NL, Casebeer LL, Kristofco R, Collins BC. Family physicians' information seeking behaviors: a survey comparison with other specialties. BMC Med Inform Decis Mak. 2005:5:9.

37. Cook DA, Levinson AJ, Garside S, Dupras DM, Erwin PJ, Montori VM. Internet-based learning in the health professions. JAMA. Sep;300(10):1181. Available from: http://jama.jamanetwork.com/article.aspx?doi=10.1001/jama. 300.10.1181.

\section{Publisher's Note}

Springer Nature remains neutral with regard to jurisdictional claims in published maps and institutional affiliations. 